\title{
Gas Atomization of Amorphous Aluminum Powder: Part II. Experimental Investigation
}

\author{
BAOLONG ZHENG, YAOJUN LIN, YIZHANG ZHOU, and ENRIQUE J. LAVERNIA
}

\begin{abstract}
The optimal processing parameters that are required to atomize amorphous $\mathrm{Al}$ were established on the basis of numerical simulations in part I of this study. In this part II, the characterization of cooling rate experienced by gas-atomized, Al-based amorphous powders was studied via experiments. An experimental investigation was implemented to validate the numerical predictions reported in part I of this study. The cooling rate experienced by the powders, for example, was experimentally determined on the basis of dendrite arm spacing correlations, and the results were compared with the numerical predictions. The experimental studies were completed using commercial Al 2024 as a baseline material and $\mathrm{Al}_{90} \mathrm{Gd}_{7} \mathrm{Ni}_{2} \mathrm{Fe}_{1}$ metallic glass (MG). The results showed that the cooling rate of droplets increases with decreasing particle size, with an increasing proportion of helium in the atomization gas and with increasing melt superheat. The experimental results reported in this article suggest good agreement between experiments and numerical simulations.
\end{abstract}

DOI: $10.1007 / \mathrm{s} 11663-009-9277-4$

(C) The Author(s) 2009. This article is published with open access at Springerlink.com

\section{INTRODUCTION}

A two-part investigation is described in this article with the ultimate goal of establishing optimal processing parameters and providing insight into the relationship between thermal conditions and microstructural evolution during gas atomization (GA) of amorphous $\mathrm{Al}$ powder. In part $I^{[1]}$ we described the numerical framework used to predict the thermal profile that is present during GA Al-based amorphous powder. More specifically, the numerical simulations were based on the assumption of Newtonian cooling with forced convection. The energy balance, gas dynamics, droplet dynamics, and heat transfer between gas and droplet were considered. To render the problem tractable, the phase transformation, crystal nucleation, and growth were ignored during $\mathrm{Al}$ droplet solidification. The modeling results were used to optimize process parameters for GA of Al-based amorphous powder, and these findings showed that the cooling rate of droplets increases with decreasing powder size and can reach in excess of $10^{5} \mathrm{~K} / \mathrm{s}$ for powder $<20 \mu \mathrm{m}$ in diameter. Gas composition has more significant effects on cooling rate than gas pressure, and 100 pct He has the highest cooling effect. Based on the modeling results and analysis, the optimized processing parameters for GA of Al-based amorphous powder are atomization gas composition of $100 \mathrm{pct} \mathrm{He}$, atomization pressure approximately $2.76 \mathrm{MPa}$, and melt superheat temperature of $1373 \mathrm{~K}$.

BAOLONG ZHENG and YAOJUN LIN, Post-Doctoral Researchers, YIZHANG ZHOU, Associate Researcher, and ENRIQUE J. LAVERNIA, Distinguished Professor, are with the Department of Chemical Engineering and Materials Science, University of California-Davis, Davis, CA 95616. Contact e-mail: bzheng@ucdavis.edu.

Manuscript submitted November 18, 2008.

Article published online August 26, 2009.
In this part II of the study, we describe a series of experiments completed with GA of commercial quality Al 2024 and $\mathrm{Al}_{90} \mathrm{Gd}_{7} \mathrm{Ni}_{2} \mathrm{Fe}_{1}$ amorphous powders with different atomization conditions, in an effort to provide experimental validation to the numerical results, as well as to provide insight into microstructural evolution.

The relationship between second dendrite arm spacing (SDAS) and cooling rate provides a useful approach to establish the precise effect of thermal conditions on microstructure. A common approach that is frequently used to determine the droplet size-cooling rate relationship is to invoke the relationship between SDAS with cooling rate and relationship between SDAS with droplet diameter. The relationship between SDAS and the cooling rate has been experimentally determined for many alloy systems, and accordingly, extensive data are available. ${ }^{[2-9]}$ The general relationship between cooling rate and SDAS is ${ }^{[10,11]}$ : $\operatorname{SDAS}=A(T)^{-n}$, where $T$ is cooling rate in $\mathrm{K} / \mathrm{s}, A$ and $n$ are constants, and they are estimated on the basis of published results for different alloys. ${ }^{[2-9]}$ The literature shows that DAS decreases with increasing cooling rate. Higher cooling rates allow less time for lateral diffusion of the rejected solute and therefore require smaller DAS to avoid constitutional supercooling; thus, nonequilibrium microstructures can be formed during rapid solidification processing. ${ }^{[10]}$ The refinement of grain size and DAS has been shown to result from increasing cooling rate during solidification.

In the presence of a high cooling rate during solidification, secondary arms will be prevented from growing, which occurs in cellular and degenerated dendritic solidification. In such a case, the observed DAS, instead of the conventional SDAS, is known to depend on the thermal gradient and correlates with the cooling rate in the solidifying material. ${ }^{[12,13]}$

As a consequence of the featureless microstructure that is associated with amorphous powders, an indirect 
approach, which involved a traditional Al-based commercial alloy Al 2024, was used in this work. The Al 2024 was selected as a baseline material based on the fact that its composition is close to that of Al-4 wt pct $\mathrm{Cu}$, for which a published empirical equation exists ${ }^{[2]}$ that correlates the cooling rate with dendrite arm spacing. Hence, the cooling rates experienced by atomized amorphous powders were deduced on the basis of the cooling rate experienced by atomized Al 2024 alloy powders with identical GA processing conditions.

Moreover, the optimized processing parameters were further validated via gas atomization of amorphous $\mathrm{Al}$ powder of $\mathrm{Al}_{90} \mathrm{Gd}_{7} \mathrm{Ni}_{2} \mathrm{Fe}_{1}$. Al-based metallic glasses (MGs), with content exceeded 85 at pct $\mathrm{Al}$ and containing transition metal (TM) and rare earth (RE) additions, have attracted much interest in recent years because of their low cost, low density, and attractive combinations of mechanical properties, ${ }^{[14-16]}$ such as ultimate tensile strength values that have been reported to reach $1500 \mathrm{MPa}$ combined with good ductility. ${ }^{[17,18]}$ The selected $\mathrm{Al}_{90} \mathrm{Gd}_{7} \mathrm{Ni}_{2} \mathrm{Fe}_{1}$ (at pct) is a dilute alloy, in which the solute content (TM $+\mathrm{RE})$ is typically below 10 at pct. The lean solute content is designed to yield a maximum volume fraction of second phase particles no greater than 40 pct for improving the material's ductility, whereas the solute-rich alloys would result in a high volume fraction of second phases when fully devitrified. ${ }^{[19]}$ In solute-rich alloys, when the primary crystallization phase of $\alpha-\mathrm{Al}$ forms, $\mathrm{Gd}$ and $\mathrm{Ni}$ are rejected into the surrounding matrix, which then becomes strong and brittle. $^{[16,20]}$

In this article, analyses of inert gas atomized Al 2024 powders are presented based on experimental results. SDAS measurements, and the corresponding cooling rate, were correlated with powder size. The numerical and experimental results were further validated on the basis of scanning electron microscopy (SEM), X-ray diffraction (XRD), and differential scanning calorimetry (DSC) analysis of gas atomized $\mathrm{Al}_{90} \mathrm{Gd}_{7} \mathrm{Ni}_{2} \mathrm{Fe}_{1}$ amorphous powder.

\section{EXPERIMENTAL}

In our experiments, atomization of the $\mathrm{Al} 2024$ alloy melt was carried out in a confined nozzle atomizer. A schematic diagram of a GA unit is shown in Figure 1. The capabilities of the facility used in this experiment are $2073 \mathrm{~K}$ melt superheat temperature, induction heating via $25 \mathrm{~kW}$ induction generator, and inert atmosphere control down to a vacuum level of $10^{-2} \mathrm{~Pa}$.

Prior to melting and atomization, both the melting and the cooling chambers were evacuated three times via a mechanical rotary vacuum pump, each time being back filled with inert gas. The $\mathrm{Al} 2024$ (93.5 pct Al-4.4 pct Cu1.5 pet Mg-0.6 pet $\mathrm{Mn}$ in wt pet or 94.6 pet $\mathrm{Al}+2.7$ pct $\mathrm{Cu}+2.4$ pet $\mathrm{Mg}+0.4 \mathrm{pct} \mathrm{Mn}$ in at pet) and $\mathrm{Al}_{90} \mathrm{Gd}_{7} \mathrm{Ni}_{2} \mathrm{Fe}_{1}$ (at pct) alloys were induction heated in an inert gas atmosphere using a graphite crucible coated with boron nitride. A homogenization time of $10 \mathrm{~min}-$ utes was also used to ensure proper dissolution of all elements. During heating of the alloy, its temperature is

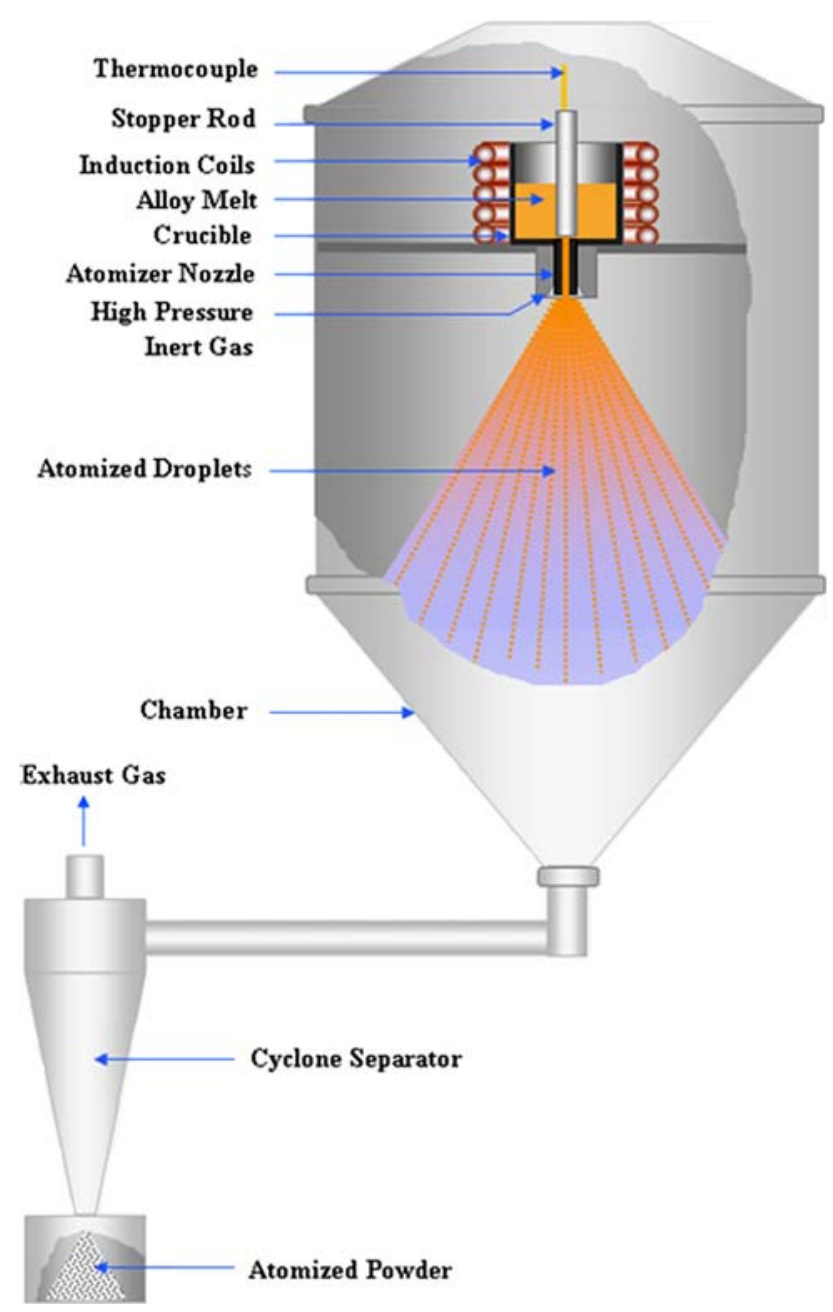

Fig. 1-Schematic diagram of gas atomization processing.

Table I. Conditions and Results for Atomizing Al 2024 Powders

\begin{tabular}{|c|c|c|c|c|c|}
\hline $\begin{array}{l}\text { GA } \\
\text { No. }\end{array}$ & $\begin{array}{c}\text { Melt } \\
\text { Temperature } \\
\text { (K) }\end{array}$ & $\begin{array}{c}\text { Gas } \\
\text { Pressure } \\
(\mathrm{MPa})\end{array}$ & $\begin{array}{l}\text { Nozzle } \\
\text { Diameter } \\
(\mathrm{mm})\end{array}$ & $\begin{array}{l}\text { GA Gas } \\
\text { (vol pct) }\end{array}$ & $\begin{array}{l}\mathrm{D}_{50} \\
(\mu \mathrm{m})\end{array}$ \\
\hline$\overline{A_{1}}$ & 1373 & 2.62 & 2.16 & 100 pct $\mathrm{He}$ & 33.37 \\
\hline $\mathrm{B}_{1}$ & 1473 & 2.62 & 2.16 & 100 pct $\mathrm{He}$ & 32.48 \\
\hline $\mathrm{C}_{1}$ & 1373 & 1.24 & 2.16 & 100 pct $\mathrm{He}$ & 38.41 \\
\hline $\mathrm{D}_{1}$ & 1323 & 5.52 & 1.7 & $\begin{array}{l}80 \text { pct } \mathrm{He} \\
+20 \text { pct } \mathrm{N}_{2}\end{array}$ & 34.45 \\
\hline
\end{tabular}

acquired by means of a thermocouple that is located inside of a stopper rod, so that melt temperature can be controlled and the alloys can be readily delivered into the atomization zone.

Tables I and II show the processing parameters used in the GA of $\mathrm{Al} 2024\left(\mathrm{~A}_{1}, \mathrm{~B}_{1}, \mathrm{C}_{1}\right.$, and $\left.\mathrm{D}_{1}\right)$ and $\mathrm{Al}_{90} \mathrm{Gd}_{7} \mathrm{Ni}_{2} \mathrm{Fe}_{1}\left(\mathrm{~A}_{2}, \mathrm{~B}_{2}, \mathrm{C}_{2}, \mathrm{D}_{2}\right.$, and $\left.\mathrm{E}_{2}\right)$ powders, respectively. The melt was delivered to the nozzle and atomized by 18 concentric jets of gas. The atomized powder was allowed to cool down to room temperature in the inert gas atmosphere of the atomizer. 
Table II. Conditions for Atomizing $\mathrm{Al}_{90} \mathrm{Gd}_{7} \mathrm{Ni}_{2} \mathrm{Fe}_{1}$ Powder

\begin{tabular}{|c|c|c|c|c|c|c|c|}
\hline \multirow[b]{2}{*}{ GA No. } & \multirow{2}{*}{$\begin{array}{c}\text { Melt } \\
\text { Temperature } \\
(\mathrm{K})\end{array}$} & \multirow{2}{*}{$\begin{array}{c}\text { Gas } \\
\text { Pressure } \\
(\mathrm{MPa})\end{array}$} & \multirow{2}{*}{$\begin{array}{l}\text { Nozzle } \\
\text { Diameter } \\
(\mathrm{mm})\end{array}$} & \multirow[b]{2}{*}{ GA Gas (vol pct) } & \multicolumn{3}{|c|}{ Powder Size $(\mu \mathrm{m})$} \\
\hline & & & & & $\mathrm{D}_{10}$ & $\mathrm{D}_{50}$ & $\mathrm{D}_{90}$ \\
\hline $\mathrm{A}_{2}$ & 1373 & 2.62 & 2.54 & 80 pct $\mathrm{He}+20$ pct $\mathrm{Ar}$ & 6.69 & 24.53 & 76.83 \\
\hline $\mathrm{B}_{2}$ & 1373 & 2.62 & 2.16 & 100 pct $\mathrm{He}$ & 8.42 & 31.88 & 77.96 \\
\hline $\mathrm{C}_{2}$ & 1473 & 2.62 & 2.16 & 100 pct $\mathrm{He}$ & 4.20 & 14.16 & 42.95 \\
\hline $\mathrm{D}_{2}$ & 1373 & 2.62 & 2.54 & 100 pct $\mathrm{He}$ & 6.23 & 25.10 & 96.27 \\
\hline $\mathrm{E}_{2}^{*}$ & 1473 & 5.52 & 3.18 & 50 pct $\mathrm{He}+50$ pct $\mathrm{N}_{2}$ & 7.01 & 20.55 & 61.60 \\
\hline
\end{tabular}

*Atomized in Ames National Lab.

Afterward, the powders were collected and sieved in air, and then classified into six different size ranges: $<25 \mu \mathrm{m}, 25-38 \mu \mathrm{m}, 38-53 \mu \mathrm{m}, 53-75 \mu \mathrm{m}, 75-106 \mu \mathrm{m}$, and $106-150 \mu \mathrm{m}$, for performing DAS measurement of atomized Al 2024 powder and microstructure investigations of atomized $\mathrm{Al}_{90} \mathrm{Gd}_{7} \mathrm{Ni}_{2} \mathrm{Fe}_{1}$ powders in different diameter classes.

SEM was used to reveal the DAS of the Al 2024 powders performed on the different size fractions. For the preparation of SEM samples, a small amount of powder samples of each size fraction was first mixed with fine conductive molding compound powder in the ratio about 1:3. A thin layer of this mixture was placed at the bottom of the mold, and the remainder of the mold was then filled with pure conductive molding compound then hot pressed at a temperature of $423 \mathrm{~K}$ and pressure of $29 \mathrm{MPa}$. The mounted samples were then ground with emery papers, polished with diamond suspension solution to $0.1 \mu \mathrm{m}$ finish using standard metallographic methods, and etched with Keller reagent $\left(1.5\right.$ pct $\mathrm{HCl}+1.0$ pct $\mathrm{HF}+2.5$ pct $\mathrm{HNO}_{3}+95$ pct $\mathrm{H}_{2} \mathrm{O}$, vol pct) for metallographic examination. Specimen preparation for topographical imaging of the powder surfaces in the SEM was done by dispersing the powder onto double-carbide-sided tape with an aluminum alloy holder. The morphology of the amorphous and crystalline phases of, as well as the overall characteristics of the atomized $\mathrm{Al}_{90} \mathrm{Gd}_{7} \mathrm{Ni}_{2} \mathrm{Fe}_{1}$ powder as a function of size, were investigated with SEM, transmission electron microscopy (TEM), XRD, and DSC.

\section{RESULTS FOR Al 2024 POWDER}

Figure 2 shows the change in the size distribution of atomized Al 2024 alloy powders for different GA conditions. The average powder size decreases with increasing amounts of melt superheat temperature, as evident from the $\mathrm{B}_{1}$ results. Increasing gas pressure can decrease powder size, as is evident from comparing the results from atomization $\mathrm{C}_{1}$ and $\mathrm{A}_{1}$, which correspond to a pressure increase from 1.24 to $2.62 \mathrm{MPa}$. However, the same trend is not apparent when the gas pressure increases from 2.62 to $5.52 \mathrm{MPa}$, as is apparent from the $A_{1}$ and $D_{1}$ results. This result is consistent with the calculation results as reported in Figure 7 of part $I^{[1]}$ The effect of gas pressure on the decreasing droplet size

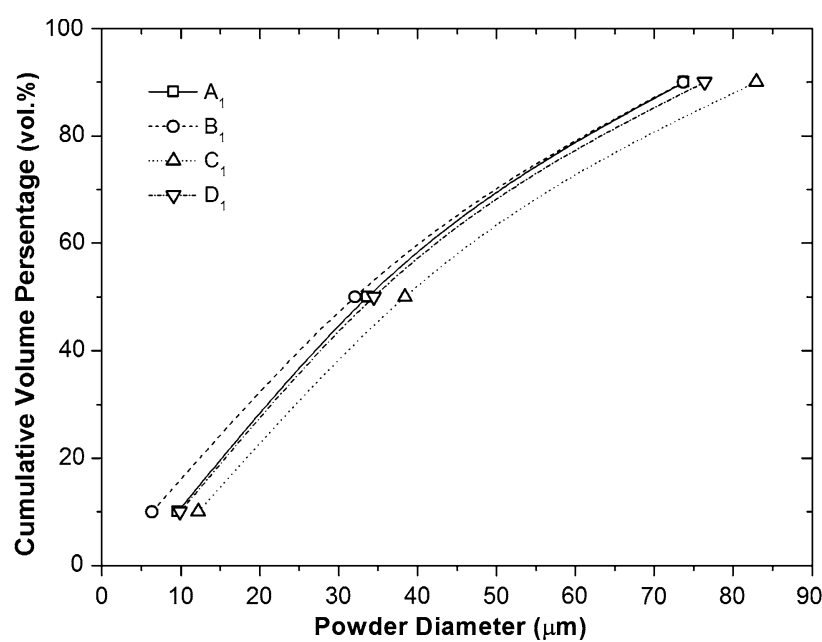

Fig. 2-Variation of atomized $\mathrm{Al} 2024$ powder size distribution.

is not apparent when gas pressure is higher $2.62 \mathrm{MPa}$ because of aspiration effects.

The atomized Al 2024 powders exhibited a typical rapid solidification microstructure consisting of a fine dendrite structure. Figure 3 shows the typical SEM microstructure of dendrite features from different size ranges from the atomized Al 2024 powders. The microsized dendrites exhibited well-defined primary arms and some secondary arms. The fine scale of the microstructure, which is evident from this figure, may be attributed to the high rate of rapid solidification resulting from the highly nonequilibrium conditions that are present during GA.

Based on these SEM observations, the DAS of different size powders was measured approximately 20 times, and a mean data of the measurements used is shown in Figure 4. The extent of microstructural refinement, as measured by the DAS, was inversely related to the powder diameter. The relationships between average powder size, $d$, and DAS were derived using the curve-fitting technique, given as follows:

$$
\mathrm{DAS}=a d+b
$$

where $a$ changes between 0.009 to 0.014 , and $b$ changes between 0.4 to 0.9 .

To evaluate the relationship between DAS and the cooling rate of the above powders, an empirical equation for gas-atomized Al-4 wt pct alloy powders, whose 


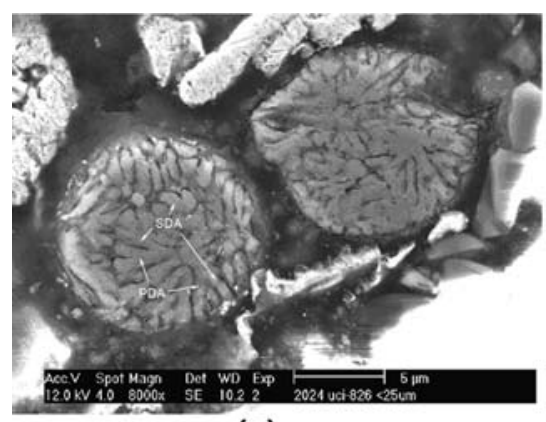

(a)

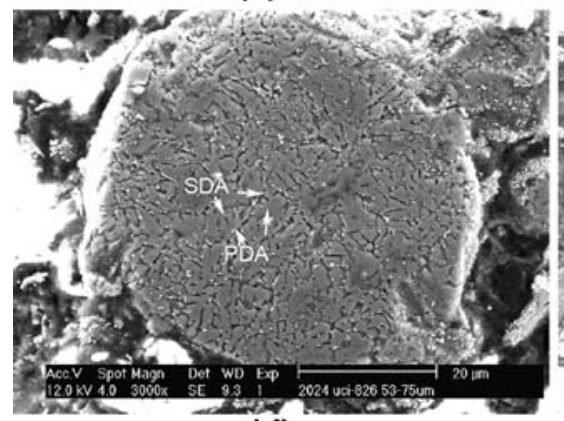

(d)

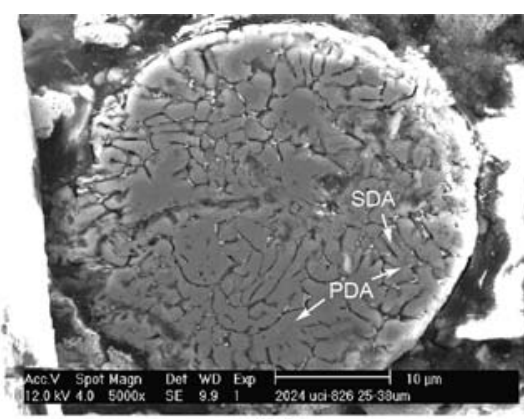

(b)

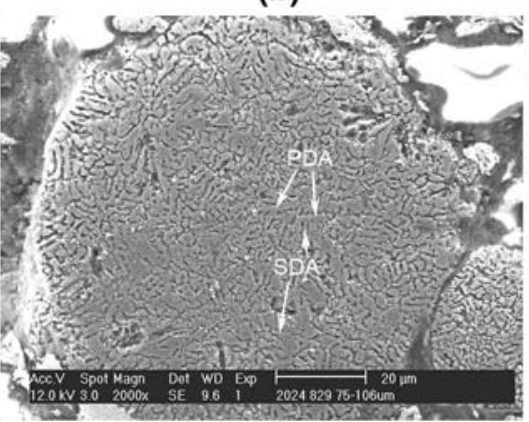

(e)

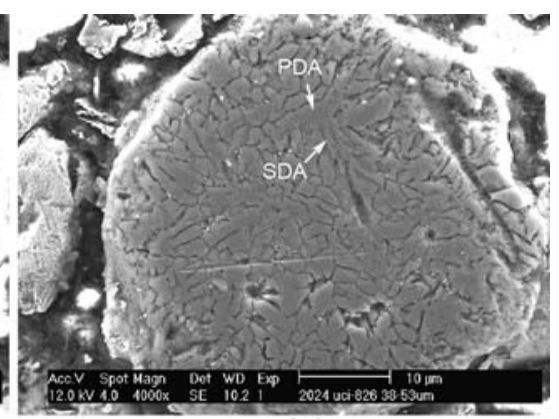

(c)

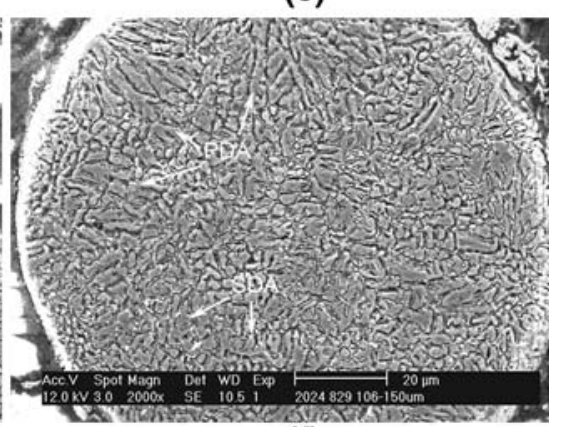

(f)

Fig. 3-SEM micrograph of atomized Al 2024 powder of cross sections (case $\mathrm{A}_{1}$ ): (a) $<25 \mu \mathrm{m}$, (b) 25-38 $\mu \mathrm{m},(c) 38-53 \mu \mathrm{m},($ d $) 53-75 \mu \mathrm{m}$, (e) 75-106 $\mu \mathrm{m}$, and (f) 106-150 $\mu \mathrm{m}$.

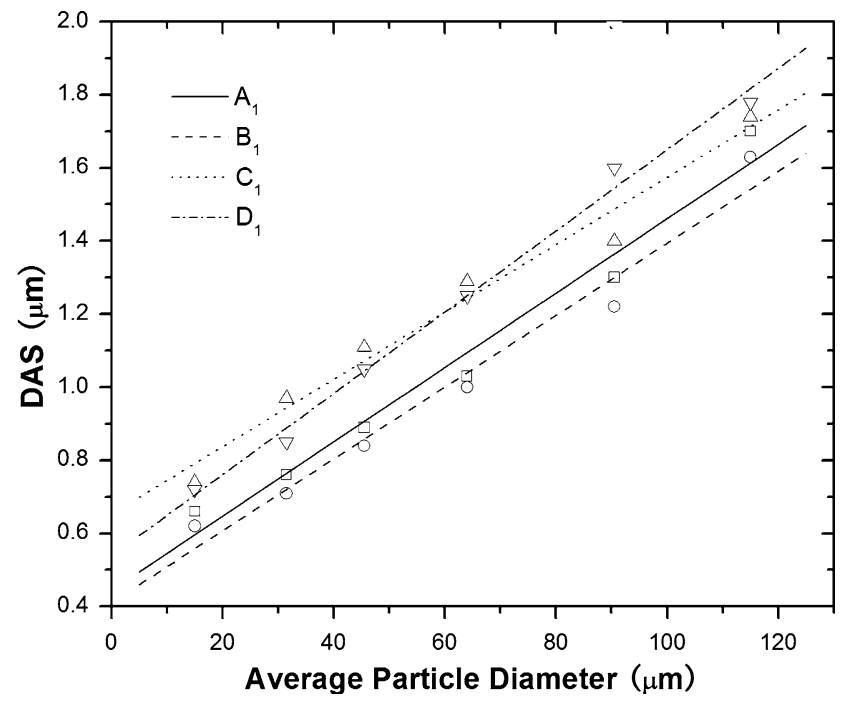

Fig. 4-Variation of DAS with Al 2024 powder size in different conditions.

composition is closed to $\mathrm{Al} 2024$, was chosen for the present study. ${ }^{[2]}$ It is given as follows:

$$
\mathrm{DAS}=50 T^{-0.333}
$$

The cooling rates were calculated based on this equation and the measured DAS values for different size powders. The relationship between cooling rate and DAS, and cooling rate with grain size are illustrated in Figures 4 and 5, which confirm that dendrite size has a stronger dependence on the cooling rate relative to that of powder size.

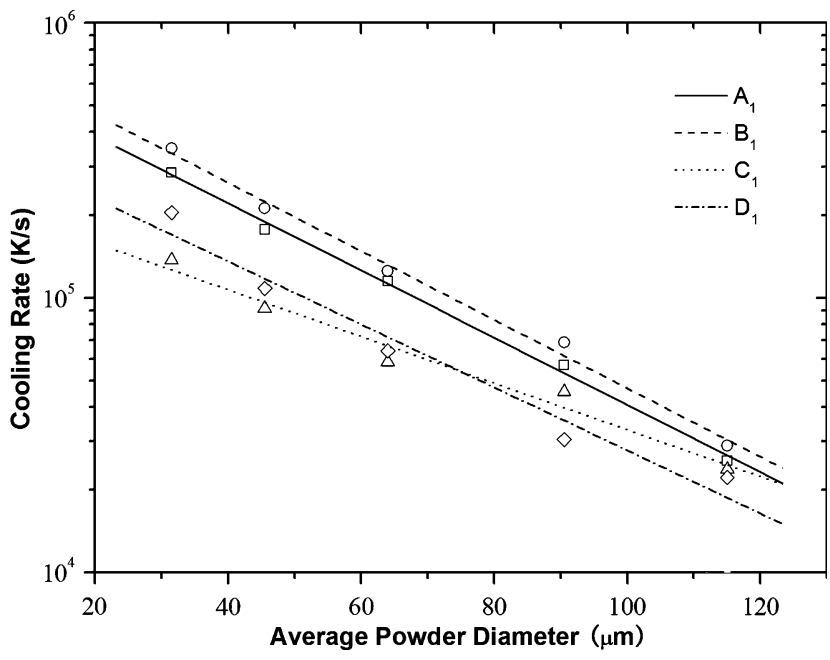

Fig. 5-Variation of cooling rate with powder size.

For the effects of the processing parameters, gas composition exerts a significant effect on the cooling rate, with 100 pct He leading to the highest cooling rate for the conditions studied herein. Comparison of the results obtained for $D_{1}$ and $A_{1}$ indicates that 100 pct $\mathrm{He}$ $\left(\mathrm{A}_{1}\right)$ has apparently increased the cooling rate of the powders over a gas mixture of 80 pct $\mathrm{He}+20$ pct $\mathrm{N}_{2}$ $\left(D_{1}\right)$, which is also in agreement with the previous numerical results. ${ }^{[1]}$ Although the change in gas composition was offset to some extent by pressure (5.52 $\mathrm{MPa})$ and nozzle diameter $(1.7 \mathrm{~mm})$, gas composition still exerted a greater effect. A higher gas pressure $(5.52 \mathrm{MPa})$ and a smaller nozzle diameter $(1.7 \mathrm{~mm})$ were used in $\mathrm{D}_{1}$, as compared with a gas pressure of 
2.62 $\mathrm{MPa}$ and a nozzle diameter of $2.16 \mathrm{~mm}$ used in $\mathrm{A}_{1}$. A high gas pressure and a small nozzle diameter, which result in a high higher gas/melt mass flow ratio, can promote a high cooling rate. This indicates that the effect of gas composition (100 pct He in $\mathrm{A}_{1}$ ) over that of 80 pct $\mathrm{He}+20$ pct $\mathrm{N}_{2}\left(\mathrm{D}_{1}\right)$ should be even more significant than that shown in Figure 5.

Gas pressure influences both powder size distribution and powder cooling rate. The numerical results ${ }^{[1]}$ indicate that of the influence of gas pressure on cooling rate decreases as gas pressure approaches a certain value, which is about $2.76 \mathrm{MPa}$ for the conditions used in this study. An experimental comparison of $\mathrm{C}_{1}$ and $\mathrm{A}_{1}$ shows that an increase of gas pressure from 1.24 to $2.62 \mathrm{MPa}$ leads to an increase in cooling rate. Based on the above results, gas composition seems to have more dominant effect on the cooling rate over that of gas pressure as evident from a comparison of $\mathrm{D}_{1}$ with $\mathrm{A}_{1}$, $\mathrm{B}_{1}$, and $\mathrm{C}_{1}$. In the experiments corresponding to $\mathrm{C}_{1}$ and $\mathrm{D}_{1}$, powders seemed to experience a similar level of cooling rate; $5.52 \mathrm{MPa}$ gas pressure and $80 \mathrm{pct} \mathrm{He}+$ 20 pct $\mathrm{N}_{2}$ were used in $\mathrm{D}_{1}$, whereas $1.24 \mathrm{MPa}$ gas pressure and 100 pct He used in $\mathrm{C}_{1}$. However, the results are inconclusive and warrant further investigation, because no direct and quantitative comparison was conducted, as far as investigating the influence of a single variable.

The results shown in Figure 5 also indicate that cooling rate increases with the increasing degree of melt superheat temperature as evident from $\mathrm{A}_{1}$ and $\mathrm{B}_{1}$ with a melt temperature increase from $1373 \mathrm{~K}$ to $1473 \mathrm{~K}$. This result is in agreement with predictions from the atomization process modeling discussed in Reference 1.

\section{RESULTS OF $\mathrm{Al}_{90} \mathrm{Gd}_{7} \mathrm{Ni}_{2} \mathrm{Fe}_{1}$ POWDER}

Figure 6 shows the powder diameter $v s$ the cumulative volume percentage of atomized amorphous $\mathrm{Al}$ powder corresponding to cases $\mathrm{A}_{2}, \mathrm{~B}_{2}, \mathrm{C}_{2}, \mathrm{D}_{2}$, and $\mathrm{E}_{2}$. It has been shown that the cooling rate or glass formation is a

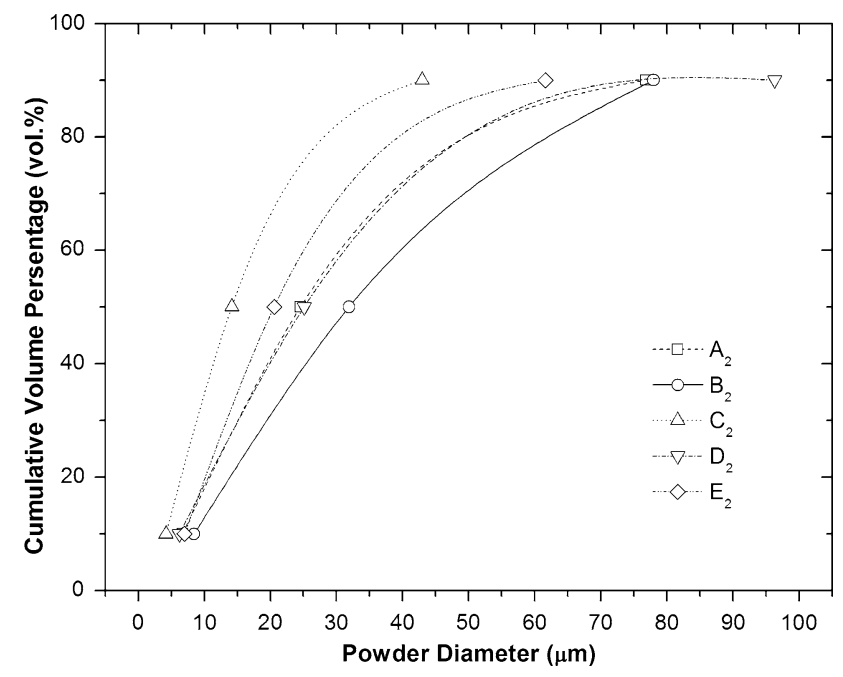

Fig. 6-Powder cumulative volume percentage $v s$ diameter for atomized Al-based amorphous powder. strong function of powder size, so that amorphous and crystal microstructures may be found in different powder size ranges for a single atomization batch. It was shown that the powder $<25 \mu \mathrm{m}$ in size contained the highest amorphous fraction, and that powder $<25 \mu \mathrm{m}$ constituted about 50 pet of the total volume.

The variables that control the production of Al-based amorphous powder via GA are primarily gas composition, gas pressure, and melt superheat temperature. These variables must be carefully monitored to achieve desired size distribution, microstructures, and properties. The effects of the primary processing parameters on powder size distribution are discussed in the following section.

\section{A. Gas Composition}

Regarding the effects of He fraction in the atomizing gas on powder size, an increase in He generally causes the powder size to decrease because of its low density, which results in an increase in gas velocity, such as shown in the numerical simulation results in Figure $7 .^{[1]}$ A comparison of gas volume consumed per unit weight of powder also showed He to be superior to other types of gas or gas mixtures. ${ }^{[1]}$ However, the cooling effects of $\mathrm{He}$ on melt viscosity also need to be considered. Comparing $\mathrm{N}_{2}$, Ar, and other gas mixtures, the higher cooling capacity of $\mathrm{He}$ gas can lead to a rapid increase in melt viscosity. In turn, an increase in viscosity will have an adverse effect on the primary breakup of the melt, as well as on secondary breakup mechanisms. This can effectively lead to an increase in powder size. This effect can be used to rationalize why case $\mathrm{B}_{2}$ showed a larger size distribution than that of case $\mathrm{A}_{2}$. However, this phenomenon can generally be neglected when gas atomizing conventional alloys.

\section{B. Gas Pressure}

Gas pressure is an important variable that has complex effects on the GA process. Generally, mass

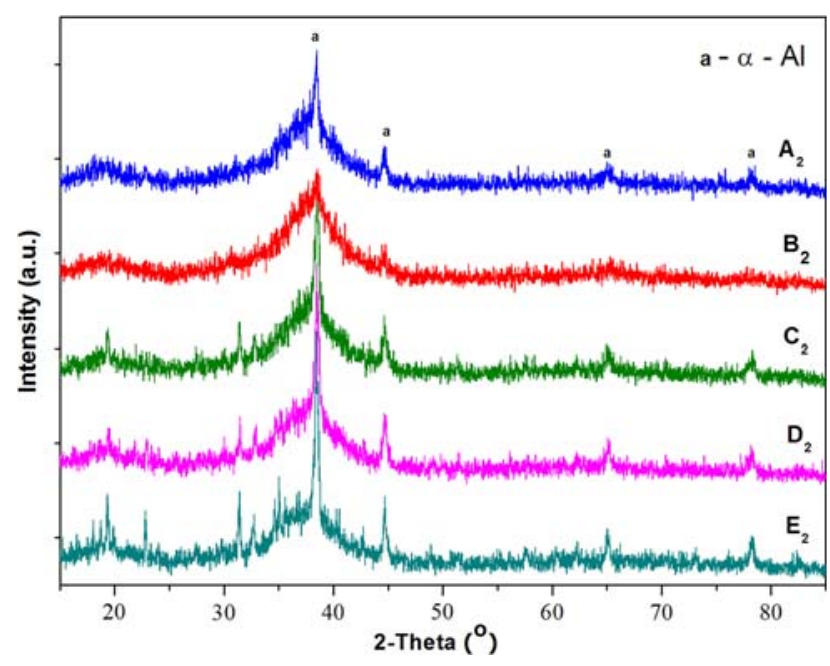

Fig. 7-XRD patterns of $\mathrm{Al}_{90} \mathrm{Gd}_{7} \mathrm{Ni}_{2} \mathrm{Fe}_{1}$ powders for different atomization conditions. 
median size $D_{50}$ decreases with increasing gas pressure as predicted on the basis of the numerical results shown in Figure $7 .^{[1]}$ If we isolate the effect of gas pressure from the aspiration effects, ${ }^{[21,22]}$ increasing gas pressure should always cause an increase in gas velocity for a given nozzle design, and if properly coupled with the melt, it should reduce the atomized droplet size by increasing the relative velocity between the droplets and gas steam. However, from Figure 6, the effect of high gas pressure on reducing atomized droplet size is not obvious when compared with the other atomization conditions (see case $\mathrm{E}_{2}$ result with gas pressure $5.52 \mathrm{MPa}$ ) because of the aspiration effect. Thompson reported an increase in average powder size with an increase in gas pressure, and this behavior was attributed to the presence of an edge flow in the reverse downstream direction along the nozzle axis, which led to an aspiration effects. The presence of a low-pressure field at the nozzle exit (aspiration effects) often leads to results that are difficult to interpret.

\section{Melt Superheat Temperature}

Melt superheat temperature plays a role in several ways; for example, the physical properties of melt will change with temperature. Cases $\mathrm{B}_{2}$ and $\mathrm{C}_{2}$ had different degrees of melt superheat temperature with other identical processing parameters. The experimental results of powder size distribution shown in Figure 6 suggest that increasing melt superheat temperature significantly promotes a finer powder size distribution. This phenomenon is primarily caused by the dependence of the melt viscosity on temperature. The melt viscosity, $\eta$, can radically decrease with increasing melt superheat temperature for most MGs. It is well known that the equilibrium viscosity of a melt can be well described with the empirical Vogel-Fulcher-Tammann (VFT) equation. ${ }^{[23,24]}$ With increasing temperature, the melt viscosity decreases, which facilitates melt disintegration during atomization.

The powder size distribution of atomized $\mathrm{Al}_{90} \mathrm{Gd}_{7} \mathrm{Ni}_{2} \mathrm{Fe}_{1}$ powder shows more variation with different processing parameters, as shown in Figure 6, compared with that of atomized Al 2024 powder as shown in Figure 2. This observation can be attributed to a more significant variation of melt viscosity in the case of the amorphous alloy as compared to with that of conventional alloys during cooling.

In addition to changes to the viscosity, melt density, and gas/metal flow ratio, melt superheat temperature also influences nucleation during solidification, but the effect is not straightforward. On the one hand, the formation of heterogeneous nuclei may be reduced with increasing melt superheat temperature, as the energy barrier increases with increasing temperature, which can also lead to the dissolution of any impurity particles. On the other hand, the presence of an elevated melt superheat temperature can lead to chemical reactions with the crucible, and crystallization reactions may be stimulated by the presence of additional heterogeneities in the melt.

The SEM morphology and cross-section micrographs of the $\mathrm{Al}_{90} \mathrm{Gd}_{7} \mathrm{Ni}_{2} \mathrm{Fe}_{1}$ powder produced in the atomization case $B_{2}$ are shown in Figure 8, and their typical variation of as-solidified microstructure with powder size. The surface features can be approximately related to the difference in the microstructure of the powder, amorphous in the case of a smooth surface and crystalline in the case of an irregular surface. ${ }^{[25,26]}$ The surface tension and liquid metal viscosity can influence the morphology of the atomized powder; hence there is a tendency to attain a spherical morphology in the presence of low melt viscosity and high melt surface tension. The experimental observation of a spherical morphology in the $\mathrm{Al}_{90} \mathrm{Gd}_{7} \mathrm{Ni}_{2} \mathrm{Fe}_{1}$ powder supports the viscosity approximation used in part I for a marginal amorphous forming Al alloy with a fragile liquid behavior. In the larger size ranges, substantial agglomeration of small powder was observed, along with numerous small satellites, which were $<25 \mu \mathrm{m}$ in diameter. The powder $<25 \mu \mathrm{m}$ shows a featureless microstructure, which corresponds to a homogeneous etching response, indicating that no crystallization has occurred. The amorphous phase formation can be confirmed by XRD analysis shown in the former of Figure 7. The formation of an amorphous phase in the powder indicated that some fractions of the atomized droplets cooled to the temperature $<T_{\mathrm{g}}$ during flight and solidified in the absence of crystallization. However, primary crystallization from the supercooled liquid

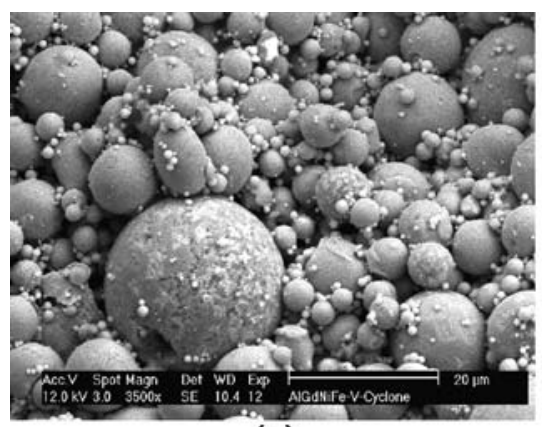

(a)

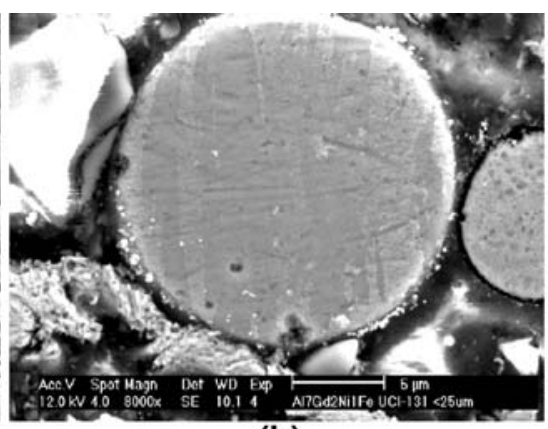

(b)

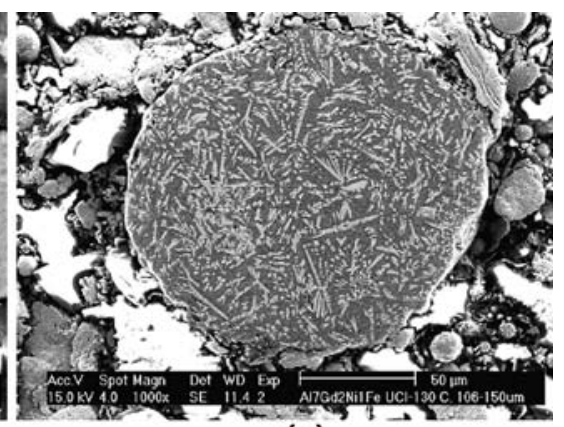

(c)

Fig. 8- SEM morphology and micrograph of atomized $\mathrm{Al}_{90} \mathrm{Gd}_{7} \mathrm{Ni}_{2} \mathrm{Fe}_{1}$ powder (Case $\mathrm{B}_{2}$ ): $(a)$ powder morphology, $(b)$ micrograph of powder $<25 \mu \mathrm{m}$, and (c) micrograph of powder 106-150 $\mu \mathrm{m}$. 


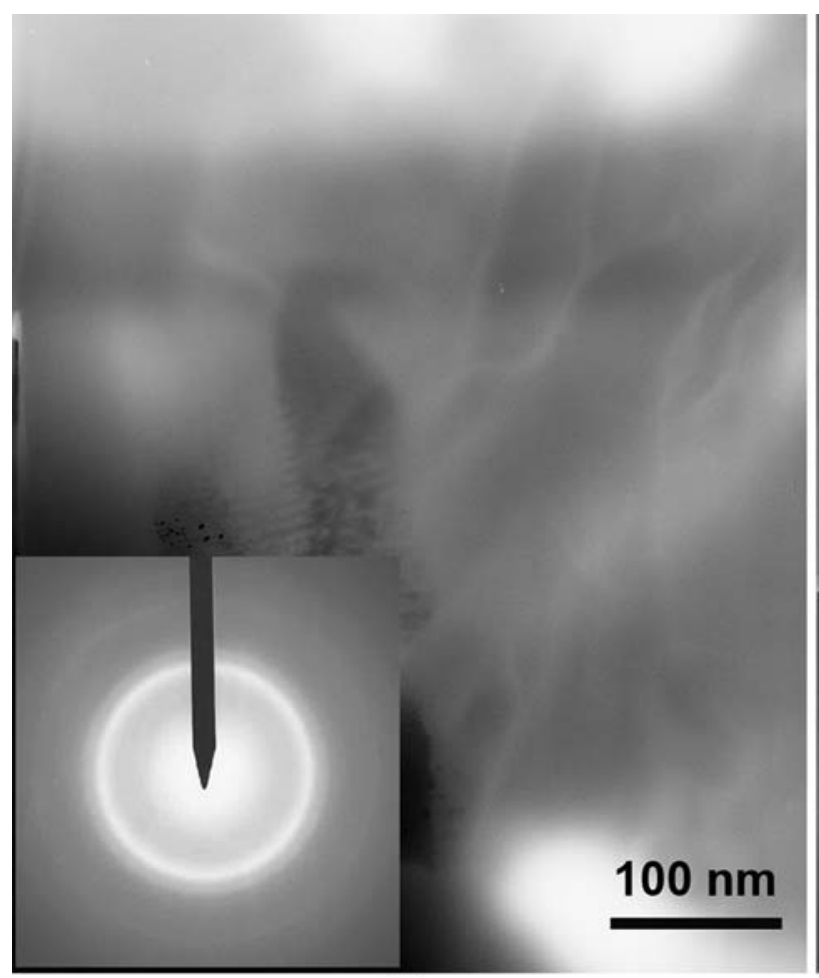

(a)

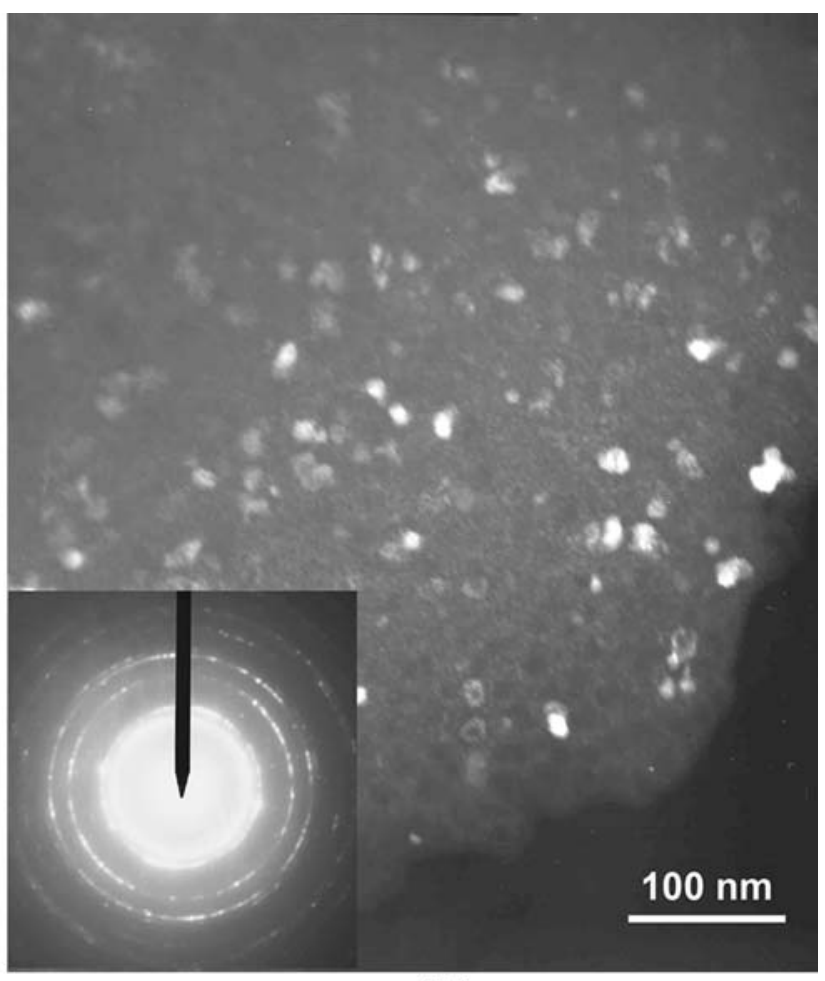

(b)

Fig. 9-TEM micrograph and selected-area diffraction pattern of $\mathrm{Al}_{90} \mathrm{Gd}_{7} \mathrm{Ni}_{2} \mathrm{Fe}_{1}$ powder $<25 \mu$ m: (a) Fully amorphous and (b) partially amorphous.

clearly occurred during solidification and was evident in larger powders $(>53 \mu \mathrm{m})$. As powder size increases, the microstructure becomes coarser and new precipitated phases appear. The amount and size of the crystal phases present increased with increasing powder size. The gas-atomized $\mathrm{Al}_{90} \mathrm{Gd}_{7} \mathrm{Ni}_{2} \mathrm{Fe}_{1}$ powder shows different microstructures depending on the powder size, which supports the premise that the cooling rate increases with decreasing powder size.

The microstructure of the powder $<25 \mu \mathrm{m}$ was studied using TEM. Some powders, which seem featureless in SEM observations, show completely amorphous microstructure as shown in Figure 9(a), which corresponds to the bright field image and corresponding selected-area diffraction pattern. Other powders, which seem to be amorphous during SEM studies, were shown to actually consist of fcc-Al nanocrystals of about 5-20 nm in size, surrounded by an amorphous matrix as shown in the micrograph of Figure 9(b) along with its selected area diffraction pattern, which show fcc$\mathrm{Al}$ diffraction rings. From SEM and TEM observations, different microstructure features are often found in different powders, even from the same size range. This difference is related to the fact that individual powders can experience different thermal and solidification environments.

Figure 7 shows XRD patterns from the $\mathrm{Al}_{90} \mathrm{Gd}_{7} \mathrm{Ni}_{2} \mathrm{Fe}_{1}$ powder $<25 \mu \mathrm{m}$ for different GA conditions corresponding to cases $A_{2}, B_{2}, C_{2}, D_{2}, E_{2}$, and $F_{2}$. The results show that powder from experiment $B_{2}$ reveals a broad diffuse halo peak, which corresponds to a main constituent phase with an amorphous structure, even though small diffraction peaks corresponding to precipitated $\alpha$-Al nanocrystals were also noted. This finding is consistent with the previous discussion on the influence of processing parameters, because a high cooling rate was attained for conditions corresponding to case $\mathrm{B}_{2}$.

The XRD patterns in Figure 7 also show the effects of increasing the degree of melt superheat temperature (cases $\mathrm{B}_{2}$ and $\mathrm{C}_{2}$ ). The powder $<25 \mu \mathrm{m}$ from case $\mathrm{C}_{2}$ shows a partial amorphous structure with fcc-Al nanocrystallites embedded in the amorphous matrix. According to the numerical results discussed in part $\mathrm{I}^{[1]}$ the cooling rate increases with increasing melt superheat temperature, which was also confirmed on the basis of GA experiments with the Al 2024 alloy. The melt superheat temperature was increased from $1373 \mathrm{~K}$ used in case $B_{2}$ to $1473 \mathrm{~K}$ used in case $\mathrm{C}_{2}$. Accordingly, case $\mathrm{C}_{2}$ corresponds to a higher cooling rate than case $\mathrm{B}_{2}$. However, the experimental results revealed the opposite trend, that is, the fraction of amorphous powder in case $\mathrm{B}_{2}$ was higher than that corresponding to case $\mathrm{C}_{2}$. This observation can be rationalized by the fact that the cooling rate required to form a fully amorphous structure for a higher degree of melt superheat is much higher than that for the case of lower melt superheat, as shown in Figure 10. This figure schematically shows TTT curves with two different cooling lines varying with different degrees of melt superheat temperature, and it is used to explain the reason why an expected higher cooling rate did not result in fully amorphous powder. Overall, comparing the XRD results from $\mathrm{A}_{2}, \mathrm{~B}_{2}$, and 


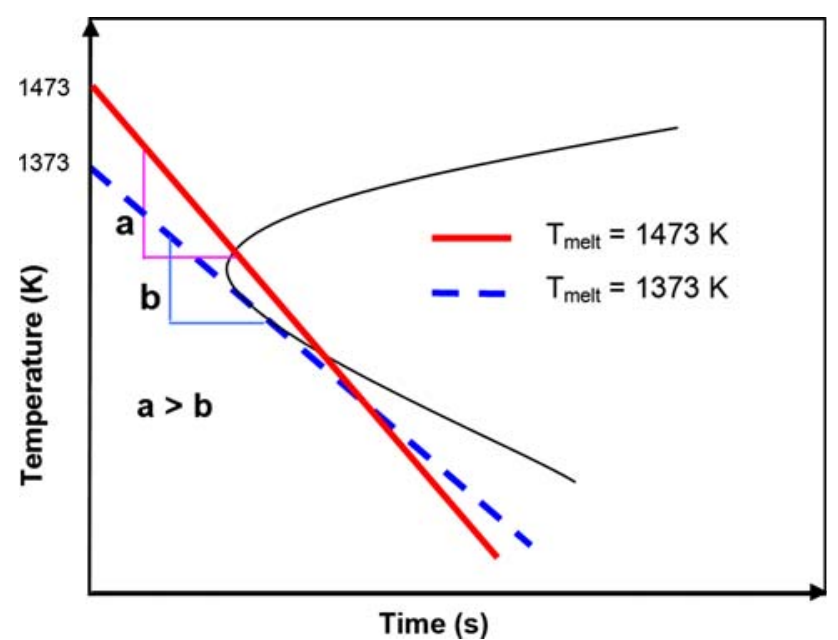

Fig. 10-Schematic TTT curve and variation of cooling rate for different melt superheat temperature values.

$\mathrm{C}_{2}$ powder and their processing parameters used, a melt superheat temperature of $1373 \mathrm{~K}$ is preferred for gas atomizing Al-Gd-Ni-Fe amorphous powder.

In case $\mathrm{D}_{2}$, high gas pressure $5.52 \mathrm{MPa}$, and $50 \mathrm{pct}$ He were used during $\mathrm{GA}$ of $\mathrm{Al}_{90} \mathrm{Gd}_{7} \mathrm{Ni}_{2} \mathrm{Fe}_{1}$ powder, whereas a gas pressure $2.62 \mathrm{MPa}$ and 100 pct He were used in case $\mathrm{B}_{2}$. The gas pressure was increased more than 50 pct in an effort to offset the He fraction, which was 50 pet $\mathrm{He}$ in case $\mathrm{D}_{2}$. However, the XRD pattern for $\mathrm{D}_{2}$ powder shows peaks from various phases, which suggests that the effect of increasing high gas pressure on increasing cooling rate is less effective than that of increasing the He fraction. This result is in agreement with the numerical results ${ }^{[1]}$ and experimental validation of cooling rate with Al 2024 powder.

Figure 11 shows DSC traces obtained during heating the $\mathrm{Al}_{90} \mathrm{Gd}_{7} \mathrm{Ni}_{2} \mathrm{Fe}_{1}$ alloy powder. The onset of primary crystallization occurs at $458 \mathrm{~K}$, and the second and third crystallization reactions occur at $633 \mathrm{~K}$ and $663 \mathrm{~K}$, respectively. These facts indicate that precipitation occurs with increasing temperature. The broad peak in the lower temperature regime is caused by precipitation of the fcc-Al phase. With increasing powder size, the morphology of the DSC curves is similar to that obtained from annealed power, which does not show any exothermic reactions, indicating a fully crystalline structure.

The volume fraction of amorphous phase in each as atomized powder size range was estimated through a comparison of the exothermic peak area of the DSC curve obtained from partial amorphous powder with that corresponding to the exothermic peak area of fully amorphous powder from case $\mathrm{B}_{2}$, and using the same heating conditions. The area corresponding to the exothermic peak decreases with increasing powder size confirming the trend that amorphous fraction decreases with increasing powder size.

Figure 12 shows the amorphous volume fractions contained in the powder $<25 \mu \mathrm{m}$ from the different atomization experiments. The $\mathrm{Al}_{90} \mathrm{Gd}_{7} \mathrm{Ni}_{2} \mathrm{Fe}_{1}$ powder

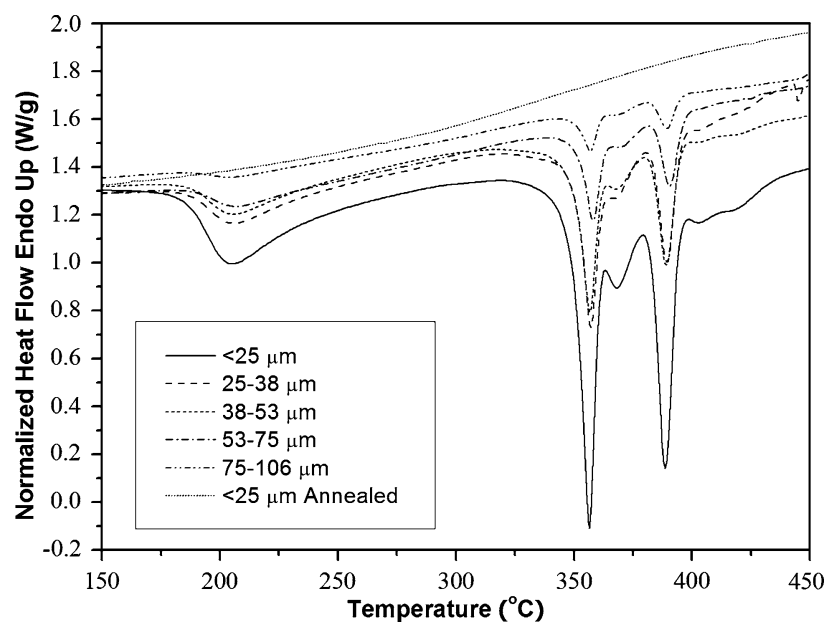

Fig. 11-Size-dependent DSC patterns of $\mathrm{Al}_{90} \mathrm{Gd}_{7} \mathrm{Ni}_{2} \mathrm{Fe}_{1}$ powders (case $\mathrm{D}_{2}$ ).

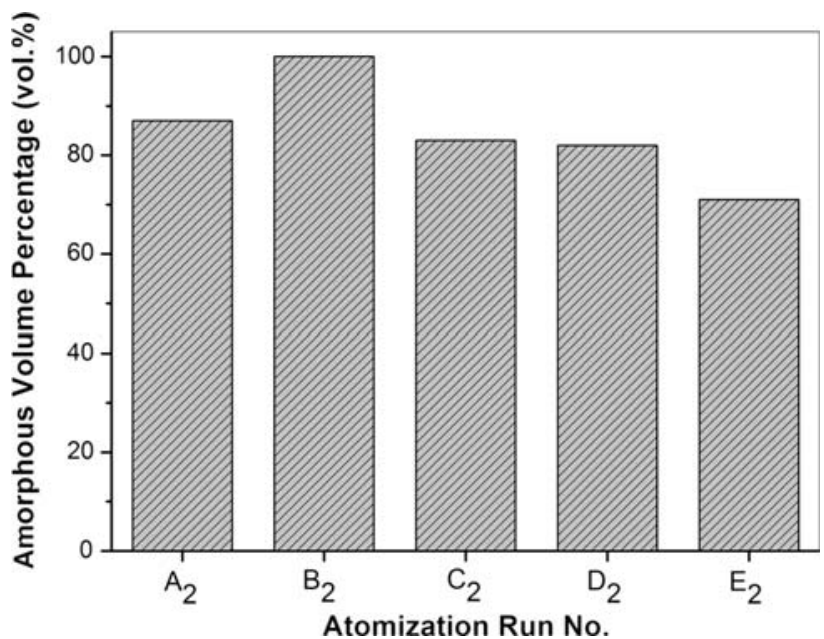

Fig. 12-Amorphous volume percentage of $<25 \mu \mathrm{m}$ powder with different atomization conditions.

$\mathrm{B}_{2}$ shows the highest amorphous fraction as compared with other cases. A higher gas pressure of $5.52 \mathrm{MPa}$ did not correspond to a higher amorphous fraction, as shown in case $\mathrm{E}_{2}$.

\section{DISCUSSION}

An experimental method has been proposed and implemented for determining the influence of powder size related on cooling rate for Al-based $\mathrm{MG}$ powders during GA. Experimental data have been used to estimate the cooling rates achieved in GA from the scale of the DAS of solidified Al 2024 powders.

The results demonstrate that DAS is a better predictor of cooling rate than powder size. The cooling rates estimated by this method are higher for He than for Ar. A numerical analysis of the cooling rate shows that the 
droplet cooling rate increases with decreasing droplet size for a given set of experimental parameters and that the cooling rate can exceed more than $10^{5} \mathrm{~K} / \mathrm{s}$ for a $<25 \mu \mathrm{m}$ powder.

A comparison of the numerical results (Figure 11, $\sim 1.5 \times 10^{6} \mathrm{~K} / \mathrm{s}$ for $20 \mu \mathrm{m}$ powder) in part $\mathrm{I}^{[1]}$ with those obtained experimentally (Figure $5, \sim 4.5 \times 10^{5} \mathrm{~K} / \mathrm{s}$ for $20 \mu \mathrm{m}$ powder) shows that numerical analysis tends to overestimate slightly the magnitude of the cooling rate. This discrepancy can be attributed to six factors. First, cooling is present during melt disintegration, which is not taken into account by the present numerical framework. Second, recirculation of the gas inside of the chamber is likely to affect both powder velocity and cooling rate, as gas temperature will likely be changing. Third, the amount of thermal energy in the near nozzle region is likely to be higher than that assumed by the numerical framework, because powder density in this regime is high. Fourth, solid-state cooling in the cyclone separator is likely to promote some coarsening of the DAS. Fifth, to keep the problem tractable, the numerical model described herein incorporates a series of limiting assumptions, such as those associated with the thermal and flow fields during atomization (e.g., compressibility effects and droplet-droplet interactions). Sixth, the values of the physical parameters of the melt and gas are not accurately known, and hence best available estimates were used.

In the case of GA of MG powders, the numerical results and the sequent experimental validation indicated that the two most important factors for achieving a cooling rate are gas composition and powder size. Similar to the influence of cooling media, gas composition has a significant influence on cooling rate. The effects of gas pressure on cooling rate involve a reduction in powder size and an increase in the relative velocity between gas and droplets. It is widely accepted that increasing gas pressure can yield a high fraction of fine powders and that these fine powders should experience higher cooling rate. In fact, small droplets can rapidly attain the gas velocity, which leads to a minimum in the value of the heat transfer coefficient. In addition, the experimental results show that the measured mean powder size is almost unchanged when gas pressure changes between $5.52 \mathrm{MPa}$ and $2.76 \mathrm{MPa}$ because of aspiration effects. For the same powder size, gas composition has more influence on cooling rate than gas pressure. For a specific nozzle diameter, the influence of gas/melt flow ratio on cooling rate is analogous to that of the gas pressure.

The gas-atomized $\mathrm{Al}_{90} \mathrm{Gd}_{7} \mathrm{Ni}_{2} \mathrm{Fe}_{1} \mathrm{MG}$ powder shows different microstructures and thermal response depending on the powder size and processing parameters. With decreasing powder size, formation of the nanocrystal fcc- $\mathrm{Al}$ and intermetallic compounds, such as $\mathrm{Al}_{3} \mathrm{Ni}$ and $\mathrm{Al}_{3} \mathrm{Gd}$, was suppressed. Increasing cooling rate by increasing $\mathrm{He}$ fraction in the gas mixture is more effective than that attained by increasing gas pressure. Fully amorphous $\mathrm{Al}_{90} \mathrm{Gd}_{7} \mathrm{Ni}_{2} \mathrm{Fe}_{1}$ was attained in the powder size powder $<25 \mu \mathrm{m}$. With increasing powder size, some powder $>25 \mu \mathrm{m}$ contained nanocrystal fcc-Al particles embedded in an amorphous matrix. The volume fraction of amorphous phase in each atomized powder size range decreases with increasing powder size.

The experimental and numerical results described in this and a prior study ${ }^{[1]}$ demonstrate clearly the major advantage obtained by using $\mathrm{He}$ gas and indicate that it is possible to achieve a high yield of amorphous powder for a solute-lean $\mathrm{Al}_{90} \mathrm{Gd}_{7} \mathrm{Ni}_{2} \mathrm{Fe}_{1}$ alloy. In terms of attaining the highest yield of amorphous powder, using a higher fraction of $\mathrm{He}$ in the atomization gas seems to be the best approach. However, this approach could lead to another limiting phenomenon - the premature solidification of the melt stream. Three ways of potentially mitigating this problem include increasing the orifice diameter, increasing the melt superheat temperature, and pressurizing the melt chamber. ${ }^{[27]}$

In the above discussion, the analytical and computational results were accompanied by experimental verification of the temperature profiles. However, the experimental framework is limited in that only several parameters can be studied for some specific materials and processing applications, and the results are usually based on statistical data analysis. Therefore, it is difficult to attain process optimization only through experimentation. In this sense, the numerical framework helped provide guiding information and thereby limit the amount of experimentation required.

\section{SUMMARY}

The influences of processing parameters of gas composition, gas pressure, and melt superheat temperature on thermal behavior of gas-atomized Al 2024 and $\mathrm{Al}_{90} \mathrm{Gd}_{7} \mathrm{Ni}_{2} \mathrm{Fe}_{1}$ (at pct) powders were studied, and the optimized processing parameters were validated. The average powder size of atomized MG powder was found to decrease significantly when the degree of melt superheat temperature was increased. It was also shown that a decrease in powder size was not apparent when the gas pressure was increased from 2.62 to $5.52 \mathrm{MPa}$ because of aspiration effects. The experimental results also showed that $\mathrm{Al}_{90} \mathrm{Gd}_{7} \mathrm{Ni}_{2} \mathrm{Fe}_{1}$ powder size increases when the fraction of $\mathrm{He}$ in the atomization gas mixture is increased based on rapid increases in melt viscosity.

The cooling rates experienced by GA powders have been experimentally determined from the scale of the DAS of solidified Al 2024 powders. The droplet cooling rate increases with decreasing droplet size and can exceed more than $10^{5} \mathrm{~K} / \mathrm{s}$ for powder $<25 \mu \mathrm{m}$ in size.

The gas-atomized $\mathrm{Al}_{90} \mathrm{Gd}_{7} \mathrm{Ni}_{2} \mathrm{Fe}_{1}$ powder shows different microstructures depending on the powder size. Fully amorphous powder of dilute $\mathrm{Al}_{90} \mathrm{Gd}_{7} \mathrm{Ni}_{2} \mathrm{Fe}_{1}$ alloy can be available through GA under the optimized processing condition (case $\mathrm{B}_{2}$ ). Increasing cooling rate by increasing $\mathrm{He}$ fraction in the gas mixture is more effective than that by increasing gas pressure, which is also consistent with the numerical results. Using higher melt superheat temperature results in a higher cooling rate, but it could not result in higher amorphous fraction of powder. A melt superheat temperature of $1373 \mathrm{~K}$ is preferred for gas atomizing Al-Gd-Ni-Fe amorphous powder. 


\section{ACKNOWLEDGMENTS}

The authors thank the U.S. DARPA Structural Amorphous Metals (SAM) Program (Leading Institution: The Boeing Company) and the Materials Design Institute between Los Alamos National Laboratory and College of Engineering, and the University of California Davis under Los Alamos National Laboratory contract number 25110-001-05 for financial support. The authors also thank Dr. I. E. Anderson at Ames National Laboratory for the supply of some atomized $\mathrm{Al}$ powder samples.

\section{OPEN ACCESS}

This article is distributed under the terms of the Creative Commons Attribution Noncommercial License which permits any noncommercial use, distribution, and reproduction in any medium, provided the original author(s) and source are credited.

\section{REFERENCES}

1. B. Zheng, Y. Lin, Y. Zhou, and E.J. Lavernia: Metall. Trans. B, 2009, in press. DOI: 10.1007/s11663-009-9276-5.

2. I.C. Stone and P. Tsakiropoulos: Int. J. Rapid Solid., 1992, vol. 7, pp. $177-90$

3. X. Liang, J.C. Earthman, and E.J. Lavernia: Acta Metall. Mater., 1992, vol. 40, pp. 3003-16.

4. C.H. Cáceres, C.J. Davidson, J.R. Griffiths, and C.L. Newton: Mater. Sci. Eng. A, 2002, vol. 325, pp. 344-55.
5. C. Labrecque, R. Angers, R. Tremblay, and D. Dube': Can. Metall. Q., 1997, vol. 36, pp. 169-75.

6. D. Dube, A. Couture, Y. Carbonneau, M. Fiset, R. Angers, and R. Tremblay: Int. J. Cast Metals Res., 1998, vol. 11, pp. 139-44.

7. H. Mizukami, T. Suzuki, and T. Umeda: Tetsu-to-Hagane, 1992, vol. 78 , pp. $580-86$

8. P.A. Joly and R. Mehrabian: J. Mater. Sci., 1974, vol. 9, pp. 144655.

9. S. Katayama and A. Matsunawa: Proc. ICALEO, 1984, pp. 60-67.

10. M.C. Flemings: Solidification Processing, McGraw-Hill, New York, 1974, pp. 146-54.

11. M.E. Glicksman and P.W. Voorhees: Metall. Trans. A, 1984, vol. 15 A, pp. $995-1001$

12. E.J. Lavernia, J.D. Ayers, and T.S. Srivatsan: Int. Mater. Rev., 1992, vol. 37, pp. 1-44.

13. R.W. Cahn and P. Haasen: Physical Metallurgy, 3rd ed., Elsevier, New York, NY, 1983, pp. 856-57.

14. A. Inoue: Prog. Mater. Sci., 1998, vol. 43, pp. 365-520.

15. J.H. Perepezko and R.J. Hebert: JOM, 2002, vol. 54, pp. 34-39.

16. A. Inoue and H. Kimura: Mater. Sci. Eng. A, 2000, vol. 286, pp. $1-10$.

17. Y. Kawamura, H. Mano, and A. Inoue: Scripta Mater., 2001, vol. 44, pp. $1599-604$

18. A. Inoue and H.M. Kimura: Mater. Sci. Forum, 1997, vols. 235238 , pp. $873-80$.

19. T.J. Watson, J. Lewandowski, R. Mishra, and B. Majumdar: $A$ White Paper for the DARPA SAM Program, 2001, pp. 1-21.

20. S.K. Das, J.H. Perepezko, R.I. Wu, and G. Wilde: Mater. Sci. Eng. A, 2001, vols. 304-306, pp. 159-65.

21. A. Lawley: MPIF, Princeton, NJ, 1992, p. 74.

22. J.S. Thompson: J. Inst. Met., 1948, vol. 74, pp. 101-32.

23. H. Vogel: Z. Phys., 1921, vol. 22, pp. 645-46.

24. G.S. Fulcher: J. Am. Ceram. Soc., 1925, vol. 8, pp. 339-55.

25. S. Annavarapu and R. Doherty: Int. J. Powder Metall., 1993, vol. 29, pp. 331-43.

26. B. Zheng, Y. Zhou, J.E. Smugeresky, and E.J. Lavernia: Metall. Trans. A, 2009, vol. 40A, pp. 1235-45.

27. H. Liu, E.J. Lavernia, and R.H. Rangel: Int. J. Heat Mass Transfer, 1995, vol. 38, pp. 2183-93. 